Gut, 1973, 14, 280-283

\title{
Treatment of dermatitis herpetiformis with corticosteroids and a gluten-free diet: a study of jejunal morphology and function
}

\author{
PARVEEN J. KUMAR, D. B. A. SILK, R. MARKS, M. L. CLARK, AND \\ A. M. DAWSON \\ From the Departments of Gastroenterology and Medicine, St Bartholomew's Hospital, London, and \\ St John's Hospital for Skin Diseases, Lyle Street, London
}

SUMMARY The jejunal morphological and functional response to either a gluten-free diet or corticosteroid therapy was studied in six patients with dermatitis herpetiformis. In each treatment group there were two patients with subtotal villous atrophy and one with partial villous atrophy. After treatment, in both groups, morphological improvement was seen in villous and surface cell heights, mucosal thickness, and intraepithelial lymphocyte counts. Jejunal function was assessed using the perfusion technique. Absorption of glucose from a $56 \mathrm{mM}$ solution was shown to improve. Water movement from this solution was in a secretory state in four patients (two in each group) before treatment and moved into the normal absorptive range after treatment. These results further outline the similarity between the mucosal lesion of dermatitis herpetiformis and true coeliac disease.

The association of coeliac disease with dermatitis herpetiformis is now well recognized (Marks, Shuster, and Watson, 1966; Fraser, Murray, and Alexander, 1967; Fry, Keir, McMinn, Cowan, and Hoffbrand, 1967) but the intestinal mucosal lesion is often less severe and overt malabsorption is unusual. The relationship between the two conditions and the factors dictating the severity of their manifestations in the gut in the majority of patients remain obscure. The jejunal mucosa in dermatitis herpetiformis has been shown to respond to gluten withdrawal in the majority of patients (Fry, McMinn, Cowan, and Hoff brand, 1969; Shuster, Watson, and Marks, 1968; Marks and Whittle, 1969), and relapse when gluten is reintroduced (Fry et al, 1969). The report of a patchy jejunal lesion in dermatitis herpetiformis (Brow, Parker, Weinstein, and Rubin, 1971) has, however, cast doubt upon the validity of accepting mucosal improvement as judged by a single biopsy specimen and has once again raised the question of the relationship of the gut lesion to dietary gluten.

Because of the possibility of sampling errors due to a patchy lesion, this study was undertaken using both morphological and functional criteria to assess

Received for publication 4 January 1973. the significance of gluten withdrawal. Function was assessed using the perfusion technique, as routine tests of absorption are often normal. Furthermore, in view of the observation that an improvement in jejunal morphology occurs in true coeliac disease treated with corticosteroids (Wall, Douglas, Booth, and Pearse, 1970), we have also assessed the effect of this treatment on the structure and function of the jejunal mucosa in dermatitis herpetiformis to see if there was a similar response.

\section{Patients}

Six male patients (aged 32 to 62 years) with dermatitis herpetiformis were studied. The diagnosis of the skin lesion was made on the clinical picture, the usual histological criteria on skin biopsy, and response to dapsone. None had clinical evidence of malabsorption. One group of three patients were treated with a gluten-free diet and one group of three with corticosteroids.

Patients on the gluten-free diet were assessed separately by a dietician and a physician three weeks after starting the diet and two monthly thereafter. The periods of treatment before reinvestigation were three months (W.C.), six months (C.P.), and 15 months (D.M.). 
Patients on corticosteroids maintained a normal diet and were reinvestigated after three weeks (P.C.) and six weeks (B.B. and R.B.). The dose used was $60 \mathrm{mg} /$ day of prednisolone for one week, with weekly reductions of $15 \mathrm{mg}$ to a dose of $15 \mathrm{mg}$ when it was tailed off by reductions of $5 \mathrm{mg}$ over the next three weeks. The patients were carefully monitored on weekly visits. All patients gave their informed consent.

\section{Jejunal Biopsies}

Jejunal biopsies were performed using the Crosby capsule and samples were taken just distal to the duodeno-jejunal flexure. They were first examined with a dissecting microscope, photographed, and then studied histologically.

Pre- and posttreatment biopsies were performed on the day before the functional assessment.

\section{Morphological Assessment}

The villous height, surface cell height, and mucosal thickness were blindly evaluated using the criteria laid down by Stewart, Pollock, Hoffbrand, Mollin, and Booth (1967). Counts of intraepithelial lymphocytes per 100 villous cells were also performed (Ferguson and Murray, 1971).

\section{Functional Assessment}

Jejunal function was assessed using a double-lumen perfusion technique with a proximal occlusive balloon (Sladen and Dawson, 1970), which allows the estimation of small changes in absorption over a given segment of intestine. Patients were intubated on the evening before the test, and the position of the tube was adjusted under screening so that the $30 \mathrm{~cm}$ test segment lay in the proximal part of the jejunum. Patients were perfused before and after gluten withdrawal or corticosteroid therapy. A $56 \mathrm{mM}$ glucose solution, rendered isotonic with sodium chloride, containing the non-absorbable marker polyethylene glycol (PEG), was used as the test substance. The tonicity was checked immediately before infusion. This solution was chosen as the test solution as we have previously shown that patients with dermatitis herpetiformis often have impaired glucose absorption and a tendency to secrete water and electrolytes during perfusion of the glucose solution (Kumar, Silk, Clark, and Dawson, 1972).

\section{Chemical Methods}

Glucose and electrolytes were measured by standard methods in the routine laboratory. Polyethylene glycol was measured by the turbidimetric method of Hyden (1956).

\section{Results}

MORPHOLOGY

In each group there were two patients with subtotal villous atrophy. Patients C.P. and D.M. were treated with a gluten-free diet and patients P.C. and R.B. with corticosteroids. The other two patients showed partial villous atrophy. Repeat biopsies from the same region in five of these patients before treatment (B.B., R.B., D.M., C.P., P.C.) yielded identical histology and no evidence of a patchy lesion. Five patients, regardless of the length or type of treatment, showed improvement in surface cell heights and villous heights and the mucosal thickness showed a decrease towards normal (see table). Patient D.M., however, showed no improvement and admitted to an inability to keep to a strict diet owing to domestic problems. During treatment none of the patients attained the normal range of surface cell or villous height. Intraepithelial lymphocytes were markedly increased in all patients initially, and fell on treatment; only in two patients-P.C. and R.B.- did they fall to within the upper limit of the normal range.

\begin{tabular}{|c|c|c|c|c|c|c|c|c|}
\hline \multirow[t]{2}{*}{ Patient } & \multicolumn{2}{|c|}{ Villous Height $(\mu)$} & \multicolumn{2}{|c|}{ Surface Cell Height $(\mu)$} & \multicolumn{2}{|c|}{ Mucosal Thickness $(\mu)$} & \multicolumn{2}{|c|}{$\begin{array}{l}\text { Lymphocyte Count per } 100 \\
\text { Villous Cells }\end{array}$} \\
\hline & Before & After & Before & After & Before & After & Before & After \\
\hline $\begin{array}{l}1 \text { WC } \\
2 \text { C.P. } \\
3 \text { D.M. } \\
4 \text { B.B. } \\
5 \text { P.C. } \\
6 \text { R.B. }\end{array}$ & $\begin{array}{r}112 \\
0 \\
0 \\
209 \\
0 \\
0\end{array}$ & $\begin{array}{r}242 \\
214 \\
0 \\
284 \\
230 \\
100\end{array}$ & $\begin{array}{l}19 \\
15 \\
16 \\
23 \\
17 \\
16\end{array}$ & $\begin{array}{l}25 \\
24 \\
15 \\
29 \\
25 \\
27\end{array}$ & $\begin{array}{l}406 \\
434 \\
452 \\
344 \\
417 \\
390\end{array}$ & $\begin{array}{l}314 \\
167 \\
442 \\
310 \\
173 \\
314\end{array}$ & $\begin{array}{l}66 \\
75 \\
77 \\
89 \\
67 \\
92\end{array}$ & $\begin{array}{l}37 \\
47 \\
80 \\
42 \\
34 \\
35\end{array}$ \\
\hline
\end{tabular}

Table Microscopic appearances of small intestinal mucosa and intraepithelial lymphocytes before and after treatment

1Patients 1-3 treated with gluten-free diet, 4-6 with prednisolone. 
JEJUNAL FUNCTION

Improvement in absorption of glucose occurred in all patients, irrespective of the treatment they were on (fig. 1). The pretreatment levels of glucose absorption were below normal in one and normal in the two other patients treated with a gluten-free diet, despite the grossly abnormal biopsies, while in

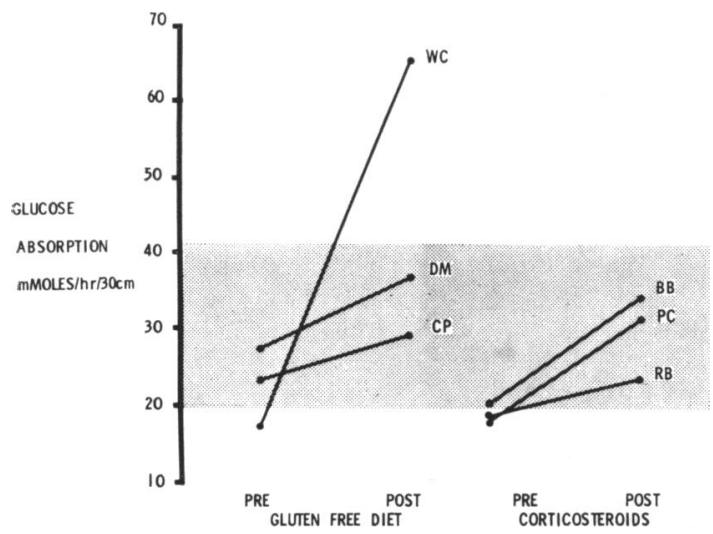

Fig. 1 Glucose absorption from a $56 \mathrm{mM}$ solution in six patients before and after treatment with either a gluten-free diet or corticosteroids. The shaded area indicates our normal range.

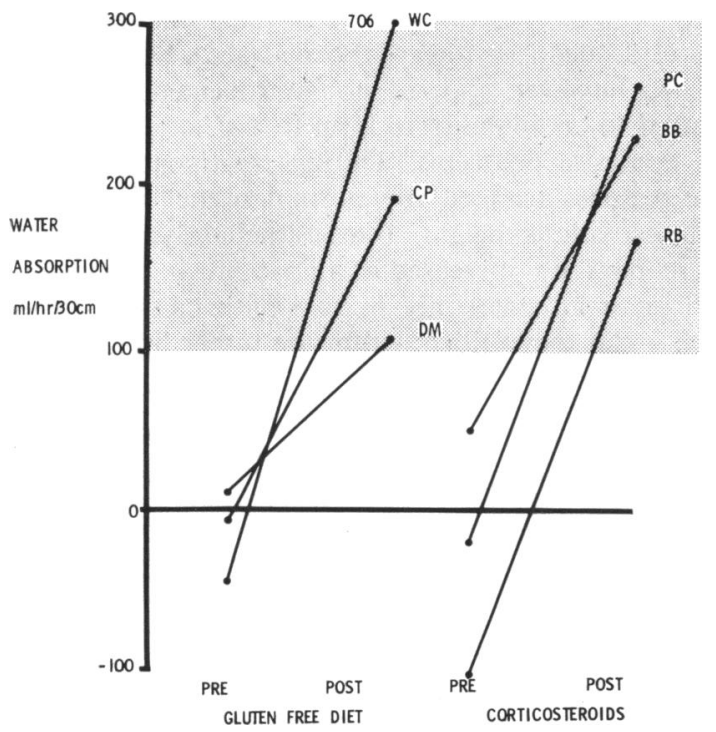

Fig. 2 Water absorption from a $56 \mathrm{mM}$ solution of glucose in six patients before and after either a glutenfree diet or corticosteroids. The shaded area indicates our normal range. the corticosteroid treated group all patients showed a low glucose absorption before treatment. One patient (W.C.) showed a dramatic improvement in glucose absorption, from below normal to above the normal range. The improvement in jejunal function would seem more striking when we consider water absorption (fig. 2). Before treatment all patients showed grossly abnormal water absorption from the glucose perfusate, and four of the six subjects showed a secretory state. Following either therapy all patients improved their absorption to well within the normal range, and even D.M. showed some improvement and just reached the lower limit of normal.

\section{Discussion}

These results have further outlined the relationship between true coeliac disease and dermatitis herpetiformis. Morphological improvement was seen with both the gluten-free diet and corticosteroid therapy in dermatitis herpetiformis, as has previously been reported in coeliac disease. Intraepithelial lymphocytes were markedly raised in all patients and fell on treatment with both regimes. This finding has previously been noted in patients with dermatitis herpetiformis treated with a gluten-free diet (Fry, Seah, McMinn, and Hoffbrand, 1972) but the numbers here are too small to compare the relative effects of gluten withdrawal and steroid therapy.

The functional significance of this morphological improvement was shown by an improvement in the absorption of glucose. It is interesting that before treatment two of the six patients showed a normal glucose absorption, despite total villous atrophy, and we have previously reported that a number of patients with grossly abnormal mucosae showed no abnormality of function in the area of proximal jejunum that was perfused (Kumar et al, 1972). The presence of a secretory state, in respect of water and electrolytes, when glucose was perfused further associates the enteropathy of dermatitis herpetiformis and true coeliac disease. A reversal of this secretory state to a normal absorptive pattern was found on both treatments, and this has been shown in our laboratory in coeliac disease with a gluten-free diet (Holdsworth and Dawson, 1965). It would be unwise to equate the morphological appearance of a single biopsy with the function of a $30 \mathrm{~cm}$ length of jejunum. However, the concomitant improvement in the functional state of the jejunum makes it unlikely that the previously reported morphological improvements with gluten withdrawal were sampling errors because of the underlying patchy lesion. It is possible that treatment improves the abnormal areas of the patchy lesion but in the study where this was noted, in only six of 22 patients was a patchy lesion 
demonstrated (Brow et al, 1971). The majority of the patients, that is 15 of 22 , showed a flat jejunal mucosa on all biopsies. In our series, so far, no evidence of a patchy lesion has been found and we would think that this is unusual in dermatitis herpetiformis. The findings here again suggest that a similarity between the mucosal lesion of dermatitis herpetiformis and true coeliac disease exists and both improve morphologically and functionally when treated with either a gluten-free diet or corticosteroid therapy.

We would like to thank the Pathology Department of St Bartholomew's Hospital, the clinicians of St John's Hospital for referring their patients, and Dr Munroe for allowing us to study one of his patients.

We are grateful to the Governors and Medical College of St Bartholomew's Hospital and the North East Metropolitan Regional Board for financial support.

\section{References}

Brow, J. R., Parker, F., Weinstein, W. M., and Rubin, C. E. (1971). The small intestinal mucosa in dermatitis herpetiformis. I. Severity and distribution of the small intestinal lesion and associated malabsorption. Gastroenterology, 60, 355-361.

Ferguson, A., and Murray, D. (1971). Quantitation of intraepithelial lymphocytes in human jejunum. Gut, 12, 988-994.

Fraser, N. G., Murray, D., and Alexander, J. O. D. (1967). Structure and function of the small intestine in dermatitis herpetiformis. Brit. J. Derm., 79, 509-518.

Fry, L., Keir, P., McMinn, R. M. H., Cowan, J. D., and Hoffbrand, A. V. (1967). Small-intestinal structure and function and haematological changes in dermatitis herpetiformis. Lancet, 2 , 729-734.

Fry, L., McMinn, R. M. H., Cowan, J. D., and Hoffbrand, A. V. (1969). Gluten free diet and reintroduction of gluten in dermatitis herpetiformis. Arch. Derm. (Chic.), 100, 129-135.

Fry, L., Seah, P. P., McMinn, R. M. H., and Hoffbrand, A. V. (1972). Lymphocytic infiltration of epithelium in diagnosis of gluten sensitive enteropathy. Brit. med. J., 3, 371-374.

Holdsworth, C. D., and Dawson, A. M. (1965). Glucose and fructose absorption in idiopathic steatorrhoea. Gut, 6, 387-391.

Hyden, S. (1956). A turbidimetric method for the determination of higher polyethylene glycols in biological material. $K$. Lantbrhögsk. Annlr., 22, 139-145.

Kumar, P. J., Silk, D. B. A., Clark, M. L., and Dawson, A. M. (1972). Jejunal function in dermatitis herpetiformis and adult coeliac disease. (Abstr.). Gut, 13, 322.

Marks, J., Shuster, S., and Watson, A. J. (1966). Small bowel changes in dermatitis herpetiformis. Lancet, 2, 1280-1282.

Marks, R., and Whittle, M. W. (1969). Results of treatment of dermatitis herpetiformis with a gluten-free diet after one year. Brit. med. J., 4, 772-775.

Shuster, S., Watson, A. J., and Marks, J. (1968). Coeliac syndrome in dermatitis herpetiformis. Lancet, 1, 1101-1106.

Sladen, G. E., and Dawson, A. M. (1970). Further studies on the perfusion method for measuring intestinal absorption in man: The effects of a proximal occlusive balloon and a mixing segment. Gut, 11, 947-954.

Stewart, J. S., Pollock, D. J., Hoff brand, A. V., Mollin, D. L., and Booth, C. C. (1967). A study of proximal and distal intestinal structure and absorptive function in idiopathic steatorrhoea. Quart. J. Med., n.s., 36, 425-444.

Wall, A. J., Douglas, A. P., Booth, C. C., and Pearse, A. G. E. (1970) Response of the jejunal mucosa in adult coeliac disease to oral prednisolone. Gut, 11, 7-14. 